\title{
A review on vehicle to vehicle communication system applications
}

\author{
Hussein Ali Ameen ${ }^{1}$, Abd Kadir Mahamad², Sharifah Saon ${ }^{3}$, Danial Md. Nor ${ }^{4}$, Kareem Ghazi $^{5}$ \\ ${ }_{1,2,3,4}$ Faculty of Electrical \& Electronic Engineering, Universiti Tun Hussein Onn Malaysia, Malaysia \\ ${ }^{1}$ Department of Computer Engineering Techniques, Al-Mustaqbal University College, Iraq \\ ${ }^{5}$ Department of Computer Engineering, University of Technology, Iraq
}

\begin{tabular}{l} 
Article Info \\
\hline Article history: \\
Received Jun 23, 2019 \\
Revised Sep 24, 2019 \\
Accepted Oct 14, 2019 \\
\hline
\end{tabular}

\section{Keywords:}

Automation

Connected vehicles

ITS

Traffic management

$\mathrm{V} 2 \mathrm{~V}$

Vehicle safety

\begin{abstract}
The field of automated vehicle technology is developing rapidly developing. While it is likely to be many years before self-driving cars are commercially viable and used in a wide range of conditions by the general public, technological advances are speeding along the automated technology continuum towards this destination. Automated vehicle technologies troth with significant social benefits such as reduced injuries and deaths, increased road efficiency, mobility. Automated vehicles can improve traffic safety, balance traffic flows, maximize road usage by offering driver warnings and/or assuming vehicle control in dangerous situations, as well as provide motorists with the best end-to-end transportation experience and reduce emissions, which are the most important goals of modern smart traffic control infrastructures. Exchanging data and integration of such systems with Vehicle-to-Vehicle (V2V) may be a keystone to successful readying of vehicular ad-hoc networks (VANETs) and will simply be the following step of this evolution, with dynamic period of time data exchange between all the players of the traffic dominant system and fostering cooperative urban quality. One of the applications of this concept is to provide vehicles and roads with the ability to make road time more enjoyable and also to make roads safer. These applications are typical examples of what an Intelligent Transportation System (ITS) is called, whose objective is to improve security by using new information and communication technologies (NTIC). In this paper, we will focus on the study of the main component in ITS systems and present a review of the major $\mathrm{V} 2 \mathrm{~V}$ benefits related to driver safety by focusing primarily on the recent developments of these systems.
\end{abstract}

Copyright $\odot 2020$ Institute of Advanced Engineering and Science. All rights reserved.

\section{Corresponding Author:}

Abd Kadir Mahamad,

Faculty of Electrical \& Electronic Engineering,

Universiti Tun Hussein Onn Malaysia,

86400 Parit Raja, Batu Pahat, Johor, Malaysia.

Email: kadir@uthm.edu.my

\section{INTRODUCTION}

The area of vehicle to vehicle (V2V) technology is speedily developing and to addressing the transportation needs of citizens symbolizes the furtherance of technology and economic growth. Global mobility and development of many cities have significantly increased the number of vehicles on roads [1]. Due to the increase in the range of the vehicles, there is a massive waste of time, and an increase in pollution is happening and from other side the degree of traffic accidents have increased considerably. Not only vehicles, however conjointly pedestrians face the security threat from traffic accidents [2-3]. After years of analysis and standardization efforts, connected vehicle technologies are nearly able to take off and commercially viable and used by the overall public in a very big selection of conditions, technological 
advancements are rushing on the automated technology time toward this destination [4]. Traffic congestion has become a problem nowadays, leading significant cities to manipulate the technology to provide better, quicker and more efficient methods to gain access. The main cause of road congestion is the drastic growth of the traffic population. However, it can be solved through proper planned road networks and intelligent traffic management strategies [5]. This new paradigm of sharing road and traffic data among vehicles in real time systems can alter a range of applications for driver assistance, safety, traffic efficiency, urban sensing and infotainment to be incorporated into modern designs of vehicles [6-7]. Primarily planned to boost driving safety and enable crash prevention through the reliable timely dissemination of warning messages among vehicles. Connected vehicle technologies are expected to satisfy the ever increasing knowledge appetence of users on wheels entailing vehicle-to-everything (V2X) interactions as shown in Figure 1. Vehicles exchange information not only with other vehicles (V2V), but also can share data with Roadside unit (V2I), however with several alternative nodes within the vehicle's neighborhood like the private communication devices of pedestrians, cyclist and charging stations [8].

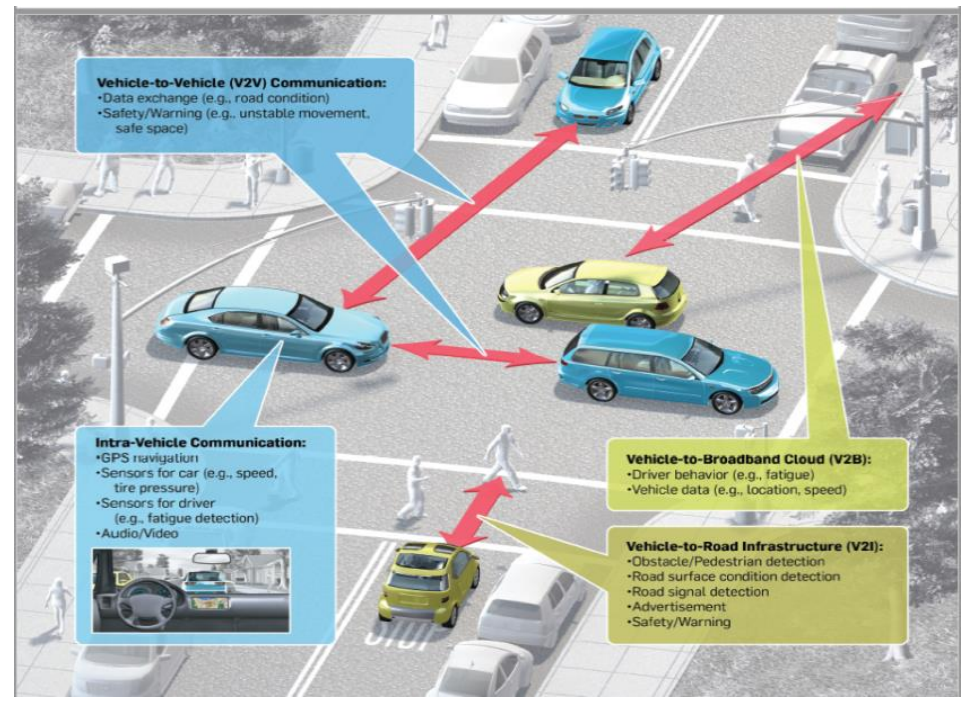

Figure 1. V2X communication system [9]

Just in Europe, around 40000 peoples die and 1.7 million are injured annually in traffic accidents. More than 16,000 crashes take place on U.S. highways every day. The reasons for an accident can vary with each different case mainly due to drowsiness, driver error, poor judgment, or distraction, driver age and gender, roadway movement and environmental conditions. The U.S. National Highway Traffic Safety Administration estimates that about 100,000 crashes are caused by driver drowsiness or fatigue each year in the U.S. alone. Thus, incorporating automatic active vehicle safety techniques such as driver detection and warning mechanisms, driver assistance tools in vehicles can contribute significantly to preventing accidents and enhancing crash survival [9-11]. New standards for connected vehicles offer unprecedented potential for data sharing and cooperation between vehicles. Vehicles are equipped with a range of on-board sensors, further as cellular and by using the IEEE 802.11p/1609.x family definition, known as the Dedicated Short Range Communication / Wireless Access Standard for Vehicle Environment (DSRC / WAVE), to facilitate vehicle communication supporting low latency, accuracy and reliability of data transmission required for V2V safety applications. These sensors and connectivity capabilities create opportunities for innovative uses for flow control, route planning, and road safety, among others [12-15]. Intelligent transport systems (ITSs) are considered to be one of the major building blocks of any smart city and it is nearly able to rollout with the aim of making the driving safer, more comfortable and smarter. Next generation ITS technologies, such as connected and automated vehicles, are finishing their last phase toward large-scale worldwide deployment. Testing of each technologies on public roads already started in different countries around the world, and serious efforts are current to control and mandate such near-future technologies. Because the autonomous and interconnected vehicle penetration in traffic will increase, many new services and applications are enabled [16-17]. These applications are a reality once emerging in vehicular networks, V2V and V2I communications are wide offered. This can be expected to be the case since have a promising future to improve traveler safety by providing warning to the drivers of dangerous conditions to take the control of 
automated vehicles to have a more secure transportation infrastructure [6, 18]. Recent technological advances in $\mathrm{V} 2 \mathrm{~V}$ communications result in the subsequent question within the context of autonomous vehicles (AVs): What traffic safety advantages and congestion relief will be bonded through the employment of $\mathrm{V} 2 \mathrm{~V}$ and/or I2V communication? [19]. The question is after we are able to deploy a fleet of absolutely autonomous driving systems that are literally safe enough to go away humans utterly out of the driving loop. A holistic solution are required, and should necessarily embody a broad appreciation for the range of challenges by all the relevant stakeholders and disciplines concerned [20]. Many research activities are presently being done by various organizations related to the real-time Vehicle to Vehicle (V2V) communication. Once absolutely enforced, V2V and V2I have the assist to help improve safety and reduce roadway traffic congestions. This article presents a review on the main innovations in $\mathrm{V} 2 \mathrm{~V}$ benefits related to driver safety. We mainly focus on the recent developments of these systems. In this review, we will analyze the main advantages and applications related to V2V system models based on 77 related articles published during the last 10 years, we present these benefits in a clear and extensive review: we first introduce the basic ideas of the automated vehicles based on $\mathrm{V} 2 \mathrm{~V}$ and point out the parts that will be different. Then, we classify the level of the automations standard according to their work that involved. The rest of the paper is organized in the following way: Section 2 presents the connected vehicle technologies, and list down the main devices used to connect the vehicles with each other based on different articles, Section 3 introduces the basic ideas and applications involved in existing V2V models extracted from various publications, Section 4 presents brief concludes the review.

\section{LEVELS OF AUTOMATIONS}

Every modern vehicle has some degree of automation, including lane centering systems, cruise control, braking systems, parking assist systems, accelerate under human driver supervision, technology that monitors the driver and even automated headlights and windshield wipers [21]. As cars become more advanced, it has become common to specify distinct levels of automation. According to the Society of Automotive Engineers (SAE) and the National Highway Traffic Safety Administration (NHTSA) are working separately but parallel development efforts, have published definitions of the levels of vehicle automation to provide a basis for communication of different concepts which had a taxonomy of the 5 levels of autonomy of vehicles. These levels ranging from level 0 which represent no automation state to levels 4 or 5 , which represent fully automation state (may require no driver at all) as shown in Figure 2 based on functional aspects of technology [22-23]. The level of automation for vehicles has been subject to a categorization and can be classified and applied to terminals and distribution centers.

\begin{tabular}{|c|c|c|}
\hline Automation Level & Modes & Terminals \\
\hline None & All driving functions assumed by user. & $\begin{array}{l}\text { All functions assumed by manually operated } \\
\text { equipment. }\end{array}$ \\
\hline Basic & $\begin{array}{l}\text { Driving assistance (e.g. cruise control), but user } \\
\text { responsible for core driving functions. }\end{array}$ & $\begin{array}{l}\text { Operation assistance (location of drop-off, storage } \\
\text { and pick up), but manually operated equipment. }\end{array}$ \\
\hline Partial & $\begin{array}{l}\text { Some driving tasks (e.g. steering, acceleration, } \\
\text { deceleration). User monitors environment and ready } \\
\text { to take control. }\end{array}$ & $\begin{array}{l}\text { Planning and managing the use of equipment and } \\
\text { storage space (Warehouse and yard management } \\
\text { systems). }\end{array}$ \\
\hline Conditional & $\begin{array}{l}\text { Perform most driving tasks and monitors driving } \\
\text { environment. User must be ready to take control at } \\
\text { request. }\end{array}$ & $\begin{array}{l}\text { Semi-automatic equipment (cranes, gantries, } \\
\text { storage stacks). Automated access to facilities } \\
\text { (automated gates). }\end{array}$ \\
\hline & $\begin{array}{l}\text { Performs all driving tasks and monitors controlled } \\
\text { driving environment. User does not need to take } \\
\text { control. }\end{array}$ & $\begin{array}{l}\text { Integration between automated handling and storage } \\
\text { systems (Fully automated terminal or warehouse). } \\
\text { Automated pick-up and deliveries. }\end{array}$ \\
\hline & $\begin{array}{l}\text { Autonomous vehicle; Performs all driving functions } \\
\text { under all environments. User provides destination, } \\
\text { but does not control vehicle. }\end{array}$ & $\begin{array}{l}\text { Autonomous terminal; responds to demand (modal, } \\
\text { intermodal, flows). }\end{array}$ \\
\hline
\end{tabular}

Figure 2. Automated Driving Levels [24]

a) Level 0 (no automation): Vehicles and equipment operated manually, that represents commonplace mechanical operations.

b) Level 1 (basic): A variety of accommodative driving assistance is provided for vehicles, primarily the ability to change speed under adaptive cruise control and still, the operator need to be in control at all times. 
c) Level 2 (partial control): Below this level of automation the vehicle is able to undertake partial control and management such as acceleration, deceleration and steering under well-defined circumstances.

d) Level 3 (conditional control): This level of automation is obtaining near really autonomous vehicles since most of the driving is automated and therefore the operator able to take control under request and more complex circumstances. The vehicle can effectively monitoring the environment by using different types of sensors.

e) Level 4 (high level control): Represents true self driving vehicles ready to perform all the specified navigation while not intervention. This would require an active monitoring and constant of the environment and the capability to adapt to changes and also still, there is an option to manually operate the vehicle.

f) Level 5 (fully controlled): A completely autonomous vehicle ready to operate in all possible environments without intervention, and also can be applied with the vehicle with remotely controllable. Users simply need to provide origin and destination information [23-24].

\section{CONNECTED VEHICLES TECHNOLOGIES}

Connected vehicles represent vehicles that use any of a variety of different communication technologies to enable the communication with the driver, other cars on the road, roadside infrastructure. This technology can be used to improve vehicle safety, vehicle efficiency and commute times. In this section includes a short review of the state-of-the-art of Automated Vehicles Technologies (AVTs); including how connected vehicle technology cooperates and complements automation. AVT falls roughly into the categories of: perception, planning and execution (exerted through actuators) as shown in Table 1.

Table 1. Automated Vehicle Technologies Used in Different Area of Applications

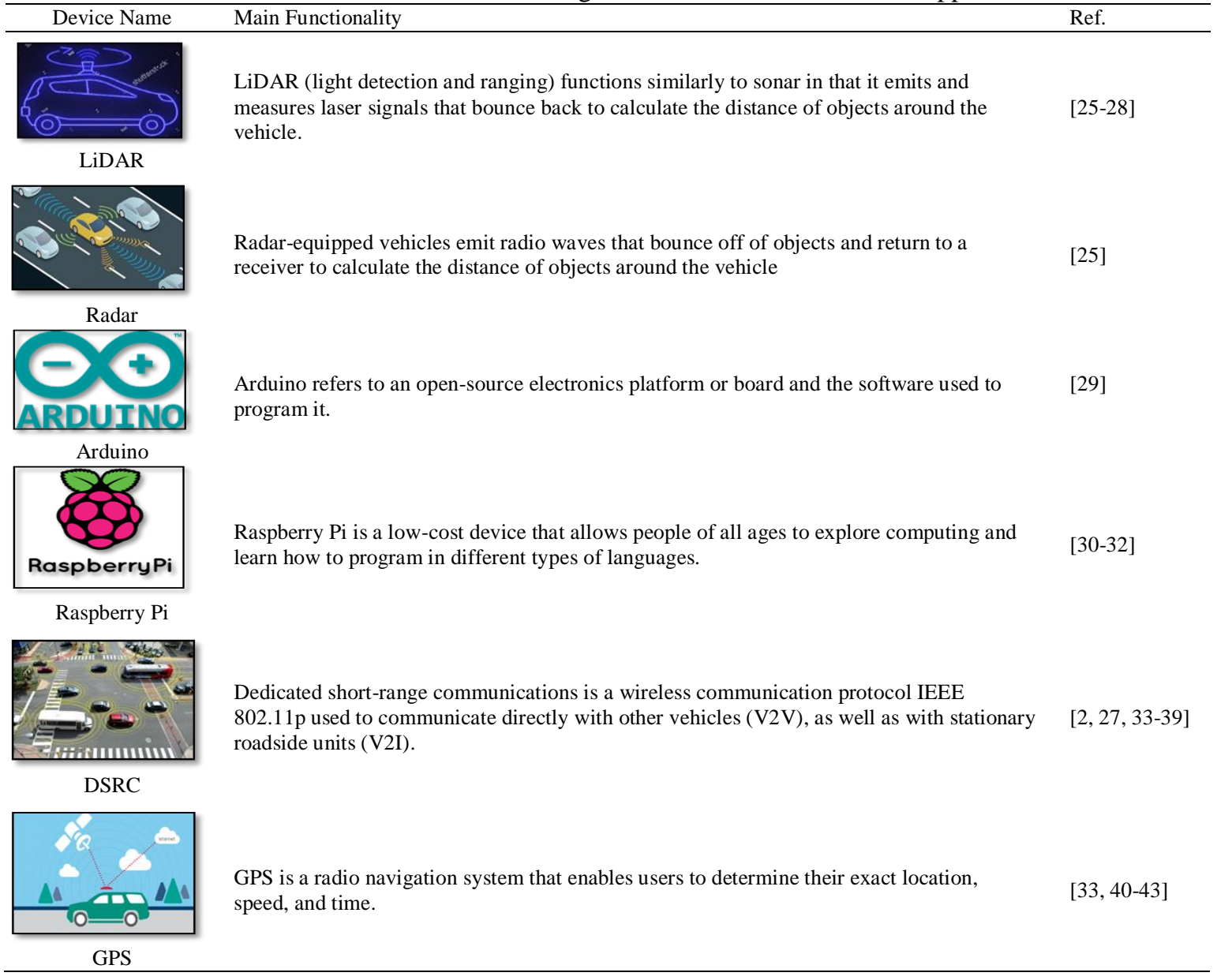




Main Functionality
Cameras allows vehicles to identify types of objects such as cars, trucks, motorcycles,
pedestrians, emergency lights, etc.

\subsection{Applications Based on V2V Technologies}

$\mathrm{V} 2 \mathrm{~V}$ communication has many applications for today's fleets such as traffic management, direction and route optimization, driver assistance applications and Safety are categorized in Figure 3. Safety applications which is perhaps one of the most promising. In each year approximately 1.35 million people die as a result of road traffic crashes. Among vulnerable road users are more than half of all road deaths: pedestrians, motorcyclists and cyclists. Road traffic injuries are the main cause of death for children and young adults between the ages of 5 and 29 [52].

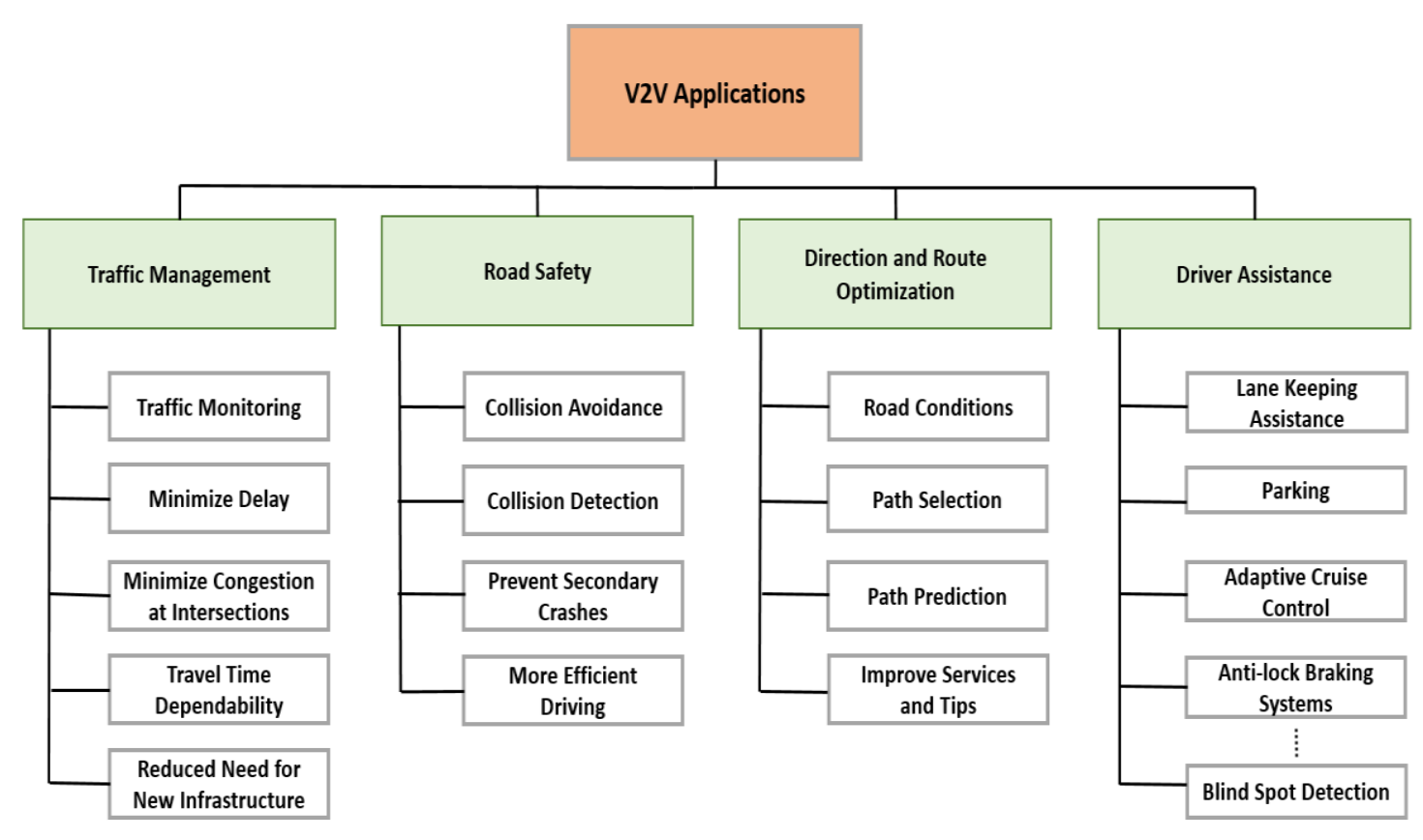

Figure 3. Applications related to V2V

\subsubsection{Traffic Management Applications}

Traffic management considered one of the main application used in $\mathrm{V} 2 \mathrm{~V}$ and this application could be eliminated heavy traffic and congestion by using the shared communication system in cars as constant lines of communication allowing drivers to avoid high traffic and congestion. The strategy for road traffic management sets goals, roles, responsibilities and operational principles. This strategy takes into consideration the organizational change in the transport administration implemented for intelligent transport, and the current challenges in terms of transport system development. The V2V communication system 
enhances traffic monitoring, management and adapting the schedule of traffic lights to reduce average delay and travel time. Provide the wireless communications to the traffic signals, traffic flow to the drivers so that the drivers can get adequate information to drive and could presents a new concept for traffic-flowoptimization [53-54], by using wide measuring of the oncoming traffic [55]. These applications used to evaluate the effectiveness and efficiency of giving control techniques [56] and fully distributed traffic information systems that enables traffic self-organization in smart cities [57-58]. The Traffic Monitoring Center (TMC) can support incident monitoring and management by exchanging vehicle information, roadside units (RSU) and infrastructure nodes [59]. Early availability provides drivers with traffic information as early as possible in order to allow them sufficient time to respond. The real-time accessibility provides available necessary traffic information at the fingertips of the drivers [59]. Road intersections are currently managed by stops or traffic lights for improving the safety. There is a growing interest in the efficiency and safety of intersections. The delays due to stop signs and red traffic lights significantly increase travel times. Allow imagining solutions for crossing an intersection or a roundabout more efficiently. With decentralized coordination between vehicles based on the freedom degrees that each vehicle has available to avoid collision [60]. A design of traffic simulation models for such vehicles for exchanging information to reduce the average delay and minimize traffic congestion for vehicles could be clearly seen in [48, 61-65]. An experimental model and simulation for pertaining the performance of IEEE $802.11 \mathrm{p}$ communication standard is used in [28] and robust decision support tool for cooperative traffic simulation [46]. Other benefits related to the traffic management is to increase the actual occurrence of planned directpassenger transfers [66] and creates an intersection environment for road users and operators [32] to bridge the gap between traffic flow modelling and communication approaches [67]. The hope is that V2V communication would allow drivers to better navigate streets and detours together and in turn reduces time spent sitting in traffic and better control the flow of traffic as well both on highways and side streets.

\subsubsection{Safety Applications}

VANETs safety application are an emerging technology that will soon be introduced into daily life. Many Intelligent Transport Systems (ITS) services that are nowadays performed with expensive infrastructure, like reliable traffic monitoring and car accident detection, can be enhanced and even entirely provided through this technology [68]. The ultimate objective of VANET safety applications is to prevent and reduce the number of road accidents which represent a delay sensitive application category, therefore to reduce the delay V2V communication is used in this category of applications [6]. Mapping the Advanced Safety Applications to the Specific Pre-Crash Scenarios [18]. Collision avoidance support systems (CASS) are now one of the most important areas of interest in road transport. These vehicle-based systems to avoid collisions by exchanging different types of useful information in (V2V) and (V2I) are among the different approaches. This information is transmitted in V2V and V2I systems to prevent accidents and provide assistance to drivers which present the most promising perspectives $[30,69]$. In order to improve the safety of driving in urban environments. These systems provide warning signals for the driver in the case that any unexpected traffic circumstance is detected, the system can act to alert the driver of collision risk and the system will be capable of autonomously avoiding collisions in traffic jam then provide incident reports based on V2V [7, 31, 47]. The system estimates an accident duration based on the time passed since the accident and provides an alternative route for vehicles approaching the accident zone to decrease waiting and travel times and avoid traffic [70]. The sharing of information between vehicles is considered to change traffic operations and enables motorists to take more proactive action to examine whether this expectation is achievable or not to reduce the risk of secondary accidents, a key objective of effective traffic incident management [38]. DSRC is an enabling technology that enables vehicles to communicate with each other in order to give the driver and/or the vehicle advance notice or warning to mitigate potential collisions. Ideally, the DSRC device could detect potential dangers before the driver could see them, such as intersection collision or a leading vehicle's sudden braking [71]. The possibility of low-cost communication opens up new opportunities in the safety management. For that reason, considering semi/fully autonomous car or smart vehicle, it is necessary that the car is capable of communicating.

\subsubsection{Direction and Route Optimization Applications}

One of the reasons fleeting, often invest in fleet management systems is to help optimize routes so drivers can get to their destinations as efficiently as possible. Vehicle communication could potentially provide drivers directly through the communication system with travel-related information. This can deliver maps, destination location and even route optimization tips. With the development of vehicle communication technologies, information can be shared between vehicles with different types of useful information, such as road conditions, with the aim of providing vehicles with a map of their vicinity on the map using V2V and V2I systems [30, 72-73]. Sensors will acquire real-time road conditions data to help drivers respond 
effectively and improve traffic efficiency by sending appropriate vehicle-to-vehicle messages to integrate available data and enhance the accuracy of vehicle location information [74]. Improving the accuracy of vehicle location and reducing the impact of multi-sensor data fusion algorithms computing time and vehicleto-vehicle communication on parallel architectures could be a good solution to sensor gaps. It would allow vehicle makers to equip their products with several inexpensive embedded proprioceptive and exteroceptive sensors [41]. Application of road congestion can provide drivers with the best routes to their destinations and also determine the best timetables for traffic lights along the overall routes that could potentially increase road capacity and prevent traffic jams [6]. Providing service for the vehicles that get stuck in the tunnels where there are merely any resources available. As GPS data and RSUs are not available in the tunnels, a focus on providing the resources to the needy vehicle by means of data transfer through multihop in clustered vehicular cloud networks is presented in [45]. The key to seeing these benefits will be widespread acceptance of the technology in all types of vehicles. A fresh idea to provide availability of the localization system and improve vehicles to exchange information with an appropriate forwarding scheme among them. These efficiency applications used to aware of the vehicle location and aiming to improve their mobility within the public roads and availability since the drivers need of the information to make decisions during the trip which becoming the voyage more secure [6]. Finally, when a bigger range of vehicles has V2V technology, the data received from different vehicles will be used to provide real time information to optimize the route.

\subsubsection{Driver Assistance Applications}

Also known as Advanced Driver Assistance Systems (ADAS) are technologies that make motor vehicles safer by improving, automating, or adapting some or all of the tasks depending on vehicle operation. With the aim of decreasing the number of deaths and injuries caused by traffic fatalities, ADAS developers try to automate the traffic perception and, in general, the driving task [69]. V2V communication can provide a platform for data exchange, expand driver support and facilitate the development of active vehicle safety systems. Driver assistance is provided by means of co-operative vehicle communication to adapt and/or share information or warnings to the drivers [9]. One of the primary active help systems supported interception sensors is focus on braking system, then traction control [75]. The next generation of driver support functions based on exteroceptive sensors are used ultrasonic sensor and rearview cameras to better assist the driver to focus on providing driver information and warnings and improving driving comfort [75]. Driver support includes simple systems such as anti-lock braking and complex systems such as fully autonomous hardware and driverless software. More complex systems that take control of the car include technologies such as machine vision, artificial intelligence (AI), radar, lasers and various positions-detecting technologies. [9]. Recently, many safety applications using V2V technology, including Forward Collision Warning (FCW), Intersection Movement Assist (IMA), Blind Spot Warning and Lane Changing Warning (BSW and LCW), Do Not Pass Warning (DNPW) and Control Loss Warning (CLW), to pre-crash scenarios that can be somewhat addressed by V2V technology $[18,76]$. Forward collision prevention systems using inexpensive, low-range and low-resolution versions of lidar sensors are currently being used for low speed applications [75]. Red Light Violation Warning (RLVW), Stop Sign Violation Warning (SSVW) systems, Road Departure Crash Warning (RDCW) is a combined application of Lateral Drift Warning (LDW) and Curve Speed Warning (CSW) [18]. Many of the published approaches are provided for advanced driver assistance systems (ADAS) instead of autonomous vehicles, but the difference becomes insignificant because of the gradual transition from ADAS to autonomous vehicles which are reasoning, environment, infrastructure, obstacle recognition and path planning and finally the automated driving [77].

\section{RESULTS}

We have analyzed several topics that are relevant from the point of view of data management and summarize some lessons learned from different publications. Automobiles and the infrastructure that supported driving has been in a slow state of evolution for more than 70 years. The pace of transformation in transportation technology to enable smart drivers has accelerated in the last two decades through the adoption of ITS, GPS, and in-vehicle safety systems. The industry is currently moving towards the transformative phase of technology evolution leading to smart cars. In order to better represent the actual context (parameters such as lane changes, high influence areas, traffic lights, and the use of topographical information provided by maps), we believe that specific attention must be given to mobility models. Simulation testing of these large scale communication schemes requires these models. Furthermore, in research carried out for vehicle networks, traffic models an interconnections with other networks must be considered. 


\section{CONCLUSION}

In this paper, we have presented a comprehensive review on the $\mathrm{V} 2 \mathrm{~V}$ communication system and attempts to evaluate the safety benefits of various connected and automated vehicles technologies, in combination, and in terms of economic costs and functional life-years saved. The growth of these new technologies has triggered an incredible transportation system evolution over the past few years. This evolution aims at making V2V system safer, more reliable, more effective and more environmentally friendly without necessarily modifying the hardware of the current infrastructure. As a part of our future activities we are planning to implement such a comprehensive framework and real time system for $\mathrm{V} 2 \mathrm{~V}$ system and focusing on large-scale deployment, configuration, operation and maintenance issues. The V2V communication technology is in theory a great way not only to further personalize the driving experience, but also to make drivers safer on the roads by giving them communication lines with each other. Because it is still relatively new, however, it will probably be a while before affordable vehicles are more widely available, making a vehicle with $\mathrm{V} 2 \mathrm{~V}$ communications more luxurious than a necessity at the moment, and we can conclude on such systems as these.

\section{ACKNOWLEDGEMENTS}

The financial support received from the TIER 1 RESEARCH GRANT: Vot U867, Office for Research, Innovation, Commercialization and Consultancy Management (ORICC), Universiti Tun Hussein Onn Malaysia is gratefully acknowledged.

\section{REFERENCES}

[1] M. A. Hannan, M. M. Hoque, A. Mohamed, and A. Ayob, "Review of energy storage systems for electric vehicle applications: Issues and challenges," Renewable and Sustainable Energy Reviews, vol. 69, pp. 771-789, 2017.

[2] L. Zhenyu, P. Lin, Z. Konglin, and Z. Lin, "Design and evaluation of V2X communication system for vehicle and pedestrian safety," The Journal of China Universities of Posts and Telecommunications, vol. 22, no. 6, pp. 18-26, December 2015.

[3] S. S. Alen Joseph Samuel, "An algorithm for IoT based vehicle verification system using RFID," International Journal of Electrical and Computer Engineering (IJECE), vol. 9, pp. 3751-3758, October 2019.

[4] N. Wang, N. Zhang, and M. Wang, "Wireless sensors in agriculture and food industry-Recent development and future perspective," Computers and Electronics in Agriculture, vol. 50, no. 1, pp. 1-14, January 2006.

[5] A. K. M. Zulnazim Dzulkurnain, Sharifah Saon, Mohd Anuaruddin Ahmadon, Shingo Yamaguchi, "Internet of things (IoT) based traffic management \& routing solution for parking space," presented at the Indonesian Journal of Electrical Engineering and Computer Science (IJEECS), July 2019.

[6] . Cunha et al., "Data communication in VANETs: Protocols, applications and challenges," Ad Hoc Networks, vol. 44, pp. 90-103, 2016.

[7] C. Liao, J. Chang, I. Lee, and K. K. Venkatasubramanian, "A trust model for vehicular network-based incident reports," presented at the 2013 IEEE 5th International Symposium on Wireless Vehicular Communications (WiVeC), 2-3 June 2013.

[8] Amadeo, C. Campolo, and A. Molinaro, "Information-centric networking for connected vehicles: a survey and future perspectives," IEEE Communications Magazine, vol. 54, no. 2, pp. 98-104, 2016.

[9] M. Faezipour, M. Nourani, A. Saeed, and S. Addepalli, "Progress and challenges in intelligent vehicle area networks," Communications of the ACM, vol. 55, no. 2, p. 90, 2012.

[10] S. S. M. F. M.Z.A.Razak, R.A.JM. Gining, M.N.F. Jamaluddin, "Data visualisation of vehicle crash using interactive map and data dashboard," Indonesian Journal of Electrical Engineering and Computer Science (IJEECS), vol. 14, pp. 1405-1411, June 2019.

[11] J. Lianghai, M. Liu, A. Weinand, and H. D. Schotten, "Direct vehicle-to-vehicle communication with infrastructure assistance in 5G network," in 2017 16th Annual Mediterranean Ad Hoc Networking Workshop (Med-Hoc-Net), 2017, pp. 1-5.

[12] Q. Chen, B. Bellows, M. P. Wittie, S. Patterson, and Q. Yang, "MOVESET: MOdular VEhicle SEnsor Technology," in 2016 Ieee Vehicular Networking Conference, O. Altintas, E. Ekici, M. Tsai, M. Sepulcre, B. Bloessl, and Y. L. Wei, Eds. (IEEE Vehicular Networking Conference, 2016.

[13] F. Yu and S. Biswas, "Self-Configuring TDMA Protocols for Enhancing Vehicle Safety With DSRC Based Vehicle-to-Vehicle Communications," IEEE Journal on Selected Areas in Communications, vol. 25, no. 8, pp. 1526-1537, 2007.

[14] Z. Liu, Z. Liu, Z. Meng, X. Yang, L. Pu, and L. Zhang, "Implementation and performance measurement of a V2X communication system for vehicle and pedestrian safety," International Journal of Distributed Sensor Networks, vol. 12, no. 9, p. 155014771667126, 2016.

[15] K. C. Dey, A. Rayamajhi, M. Chowdhury, P. Bhavsar, and J. Martin, "Vehicle-to-vehicle (V2V) and vehicle-toinfrastructure (V2I) communication in a heterogeneous wireless network-Performance evaluation," Transportation Research Part C: Emerging Technologies, vol. 68, pp. 168-184, 2016.

[16] C. Campolo, A. Molinaro, and R. Scopigno, "From today's VANETs to tomorrow's planning and the bets for the day after," Vehicular Communications, vol. 2, no. 3, pp. 158-171, 2015. 
[17] H. Menouar, I. Guvenc, K. Akkaya, A. S. Uluagac, A. Kadri, and A. Tuncer, "UAV-enabled intelligent transportation systems for the smart city: Applications and challenges," IEEE Communications Magazine, vol. 55, no. 3, pp. 22-28, 2017.

[18] T. Li and K. M. Kockelman, "Valuing the safety benefits of connected and automated vehicle technologies," in Proceedings of the 95th Annual Meeting of the Transportation Research Board, Washington, DC, USA, 2016, pp. 10-14.

[19] S. Darbha, S. Konduri, and P. R. Pagilla, "Benefits of V2V communication for autonomous and connected vehicles," IEEE Transactions on Intelligent Transportation Systems, 2018.

[20] P. Koopman and M. Wagner, "Autonomous vehicle safety: An interdisciplinary challenge," IEEE Intelligent Transportation Systems Magazine, vol. 9, no. 1, pp. 90-96, 2017.

[21] P. Lewis, G. Rogers, and S. Turner, "Beyond Speculation: Automated Vehicles and Public Policy," Eno Center of Transportation, May 2017.

[22] K. Saleh, M. Hossny, and S. Nahavandi, "Towards trusted autonomous vehicles from vulnerable road users perspective," in 2017 Annual IEEE International Systems Conference (SysCon), 2017, pp. 1-7: IEEE.

[23] T. Litman, "Autonomous vehicle implementation predictions: Implications for transport planning," Victoria Transport Policy Institute, 2015.

[24] J.-P. Rodrigue, C. Comtois, and B. Slack, "The geography of transport systems 4th edition". Jean-Paul Rodrigue (2017), New York: Routledge, 2016.

[25] K. Lidstrom et al., "A Modular CACC System Integration and Design," IEEE Transactions on Intelligent Transportation Systems, vol. 13, no. 3, pp. 1050-1061, 2012.

[26] F. Visintainer, L. Altomare, A. Toffetti, A. Kovacs, and A. Amditis, "Towards Manoeuver Negotiation: AutoNet2030 Project from a Car Maker Perspective," Transportation Research Procedia, vol. 14, pp. 2237-2244, 2016.

[27] S. Eckelmann, T. Trautmann, H. Ußler, B. Reichelt, and O. Michler, "V2V-Communication, LiDAR System and Positioning Sensors for Future Fusion Algorithms in Connected Vehicles," Transportation Research Procedia, vol. 27, pp. 69-76, 2017.

[28] A. Sassi, Y. Elhillali, and F. Charfi, "Evaluating Experimental Measurements of the IEEE 802.11p Communication Using ARADA LocoMate OBU Device Compared to the Theoretical Simulation Results," Wireless Personal Communications, vol. 97, no. 3, pp. 3861-3874, Dec 2017.

[29] A. Memon, F. K. Shaikh, and E. Felemban, "Experimental evaluation of vehicle-to-vehicle based data transfer," in 2015 International Conference on Information and Communication Technology Research (ICTRC), 2015, pp. 274-277.

[30] C. Y. Qu, D. A. Ulybyshev, B. K. Bhargava, R. Ranchal, L. T. Lilien, and Ieee, "Secure Dissemination of Video Data in Vehicle-to-Vehicle Systems," in 2015 IEEE 34th Symposium on Reliable Distributed Systems Workshop(Symposium on Reliable Distributed Systems Proceedings, 2015, pp. 47-51.

[31] F. Cardoso, A. Serrador, and T. Canas, "Algorithms for Road Safety Based on GPS and Communications Systems WAVE," Procedia Technology, vol. 17, pp. 640-649, 2014.

[32] N. Varga, L. Bokor, A. Takács, J. Kovács, and L. Virág, "An architecture proposal for V2X communication-centric traffic light controller systems," in 2017 15th International Conference on ITS Telecommunications (ITST), 2017, pp. 1-7.

[33] C. Olaverri-Monreal, P. Gomes, R. Fernandes, F. Vieira, M. Ferreira, and Ieee, "The See-Through System: A VANET-Enabled Assistant for Overtaking Maneuvers," in 2010 IEEE Intelligent Vehicles Symposium (IEEE) Intelligent Vehicles Symposium, 2010, pp. 123-128.

[34] Q. Chen, B. Bellows, M. P. Wittie, S. Patterson, and Q. Yang, "MOVESET: MOdular VEhicle SEnsor Technology," in 2016 IEEE Vehicular Networking Conference (VNC), 2016, pp. 1-4.

[35] H. Su, C. H. Cho, Y. H. Chu, W. Y. Chang, and IEEE, "A Traffic Information Dissemination Mechanism Based on DSRC/WAVE and Its Applications", (2012 12th International Conference on Its Telecommunications). 2012, pp. 629-632.

[36] A. M. Orozco, S. Cespedes, R. Michoud, and G. Llano, "Design and simulation of a collision notification application with geocast routing for car-to-car communications," European Transport Research Review, vol. 7, no. 4, Dec 2015, Art. no. 36.

[37] J. Toutouh and E. Alba, "Light commodity devices for building vehicular ad hoc networks: An experimental study," Ad Hoc Networks, vol. 37, Part 2, pp. 499-511, February 2016.

[38] H. Yang, Z. Wang, and K. Xie, "Impact of connected vehicles on mitigating secondary crash risk," International Journal of Transportation Science and Technology, vol. 6, no. 3, pp. 196-207, 9// 2017.

[39] T. Petrov, M. Dado, K. E. Ambrosch, and P. Holecko, "Experimental Topology for V2V Communication Based on Internet of Things", (2016 Elektro 11th International Conference). 2016, pp. 72-76.

[40] J. Ahrems, "Appraisal of Feasibility of Using Vehicle-to-Vehicle Communications for Safe Passage of Unsignalled Road Intersection under Varying Conditions," IFAC Proceedings Volumes, vol. 46, no. 28, pp. 84-89, 2013.

[41] F. Bounini, D. Gingras, H. Pollart, and D. Gruyer, "Real time cooperative localization for autonomous vehicles," in 2016 IEEE 19th International Conference on Intelligent Transportation Systems (ITSC), 2016, pp. 1186-1191.

[42] Y. Agarwal, K. Jain, and O. Karabasoglu, "Smart vehicle monitoring and assistance using cloud computing in vehicular Ad Hoc networks," International Journal of Transportation Science and Technology, 2017.

[43] D. Huang and M. Verma, "ASPE: attribute-based secure policy enforcement in vehicular ad hoc networks," Ad Hoc Networks, vol. 7, no. 8, pp. 1526-1535, November 2009. 
[44] M. Obst, L. Hobert, and P. Reisdorf, "Multi-sensor data fusion for checking plausibility of V2V communications by vision-based multiple-object tracking," in 2014 IEEE Vehicular Networking Conference (VNC), 2014, pp. 143-150.

[45] Y. Agarwal, K. Jain, S. Kumar, G. N. Bhardwaj, and Ieee, "TLST: Time of Arrival Based Localization and Smart Tunnel concept in VANETs" (2016 3rd International Conference on Signal Processing and Integrated Networks). 2016, pp. 779-784.

[46] M. Gueriau, R. Billot, N. E. El Faouzi, J. Monteil, F. Armetta, and S. Hassas, "How to assess the benefits of connected vehicles? A simulation framework for the design of cooperative traffic management strategies," Transportation Research Part C-Emerging Technologies, vol. 67, pp. 266-279, Jun 2016.

[47] V. Milanés, L. Alonso, J. Villagrá, J. Godoy, T. de Pedro, and J. P. Oria, "Traffic jam driving with NMV avoidance," Mechanical Systems and Signal Processing, vol. 31, pp. 332-344, Augest 2012.

[48] M. S. Rayeni, A. Hafid, and P. K. Sahu, "Dynamic spatial partition density-based emergency message dissemination in VANETs," Vehicular Communications, vol. 2, no. 4, pp. 208-222, October 2015.

[49] J. Radak, B. Ducourthial, V. Cherfaoui, and S. Bonnet, "Detecting Road Events Using Distributed Data Fusion: Experimental Evaluation for the Icy Roads Case," IEEE Transactions on Intelligent Transportation Systems, vol. 17, no. 1, pp. 184-194, 2016.

[50] Z. Sheng, W. Ying, and W. Yantong, "An embedded Node Operating System for real-time information interaction in Vehicle-to-Vehicle communication," in 2016 IEEE 19th International Conference on Intelligent Transportation Systems (ITSC), 2016, pp. 887-892.

[51] M. El-Said, V. Bhuse, and A. Arendsen, "An Empirical Study to Investigate the Effect of Air Density Changes on the DSRC Performance," Procedia Computer Science, vol. 114, pp. 523-530, 2017.

[52] P. Kocharoen, "Visible Light Communication: Importance and Thai Preparations," Procedia Computer Science, vol. 86, pp. 51-54, 2016.

[53] M. Hübner, T. Lück, and E. Schnieder, "Cooperative Control of Multi-Vehicle-Formations in Road Traffic by means of Consensus Algorithm and Petri Nets," IFAC Proceedings Volumes, vol. 42, no. 15, pp. 328-333, 2009.

[54] B. F. Ferreira, J. J. P. C. Rodrigues, J. A. Dias, and J. N. Isento, "Man4VDTN-A network management solution for vehicular delay-tolerant networks," Computer Communications, vol. 39, pp. 3-10, 15 Febraury 2014.

[55] S. Naumann, F. Wolf, and R. Schönrock, "Floating Car Observer-An innovative vehicle-sensor for urban and highway scenarios," IFAC Proceedings Volumes, vol. 43, no. 23, pp. 19-24, // 2010.

[56] M. D. do Amarante, A. L. C. Bazzan, and Ieee, "Benefits of routing and replanning with imperfect information" (2013 Ieee Symposium on Intelligent Agent). 2013, pp. 54-61.

[57] A. Gibaud and P. Thomin, "Message forwarding based on vehicle trajectory history in Fully Distributed Traffic Information Systems," Computer Communications, vol. 60, pp. 40-52, 4/1/ 2015.

[58] Z. Li and M. Shahidehpour, "Deployment of cybersecurity for managing traffic efficiency and safety in smart cities," The Electricity Journal, vol. 30, no. 4, pp. 52-61, May 2017.

[59] B. Singh, H. Hasbullah, M. Y. Nayan, B. Tahlan, and IEEE, "Early Detection of Incident using Vehicular Ad-hoc Network" (2014 International Conference on Computer and Information Sciences). 2014.

[60] M. A. Lebre, F. Le Mouel, E. Menard, and Ieee, "Resilient, Decentralized V2V Online Stop-free Strategy in a Complex Roundabout," in 2016 Ieee 83rd Vehicular Technology Conference (IEEE Vehicular Technology Conference Proceedings, 2016.

[61] P. Gora and I. Rüb, "Traffic Models for Self-driving Connected Cars," Transportation Research Procedia, vol. 14, pp. 2207-2216, 2016.

[62] V. Jindal and P. Bedi, "Reducing waiting time with parallel preemptive algorithm in VANETs," Vehicular Communications, vol. 7, pp. 58-65, January 2017.

[63] A. Grzybek, G. Danoy, P. Bouvry, and M. Seredynski, "Mitigating flash crowd effect using connected vehicle technology," Vehicular Communications, vol. 2, no. 4, pp. 238-250, October 2015.

[64] T. Y. Wu, N. Guizani, and C. Y. Hsieh, "An efficient adaptive intelligent routing system for multi-intersections," Wireless Communications \& Mobile Computing, vol. 16, no. 17, pp. 3175-3186, Dec 2016.

[65] Z. He and D. Zhang, "Cost-efficient traffic-aware data collection protocol in VANET," Ad Hoc Networks, vol. 55, pp. 28-39, February 2017.

[66] T. Liu, A. Ceder, J. Ma, and W. Guan, "CBVC-B: A System for Synchronizing Public-transport Transfers Using Vehicle-to-Vehicle Communication," Procedia - Social and Behavioral Sciences, vol. 138, pp. 241-250, 14 July 2014.

[67] D. Jia and D. Ngoduy, "Enhanced cooperative car-following traffic model with the combination of V2V and V2I communication," Transportation Research Part B: Methodological, vol. 90, pp. 172-191, Augest 2016.

[68] A. Baiocchi, F. Cuomo, M. De Felice, and G. Fusco, "Vehicular Ad-Hoc Networks sampling protocols for traffic monitoring and incident detection in Intelligent Transportation Systems," Transportation Research Part C: Emerging Technologies, vol. 56, pp. 177-194, July 2015.

[69] J. Santa, R. Toledo-Moreo, M. A. Zamora-Izquierdo, B. Úbeda, and A. F. Gómez-Skarmeta, "An analysis of communication and navigation issues in collision avoidance support systems," Transportation Research Part C: Emerging Technologies, vol. 18, no. 3, pp. 351-366, June 2010.

[70] B. Zardosht, S. S. Beauchemin, and M. A. Bauer, "A predictive accident-duration based decision-making module for rerouting in environments with $\mathrm{V} 2 \mathrm{~V}$ communication," Journal of Traffic and Transportation Engineering (English Edition), vol. 4, no. 6, pp. 535-544, December 2017.

[71] A. Tang and A. Yip, "Collision avoidance timing analysis of DSRC-based vehicles," Accident Analysis \& Prevention, vol. 42, no. 1, pp. 182-195, January 2010. 
[72] Z. Huang, Q. Wu, J. Ma, and S. Fan, "An APF and MPC combined collaborative driving controller using vehicular communication technologies," Chaos, Solitons \& Fractals, vol. 89, pp. 232-242, August 2016.

[73] Y. Allouche and M. Segal, "Cluster-Based Beaconing Process for VANET," Vehicular Communications, vol. 2, no. 2, pp. 80-94, April 2015.

[74] N. Salameh, G. Challita, S. Mousset, A. Bensrhair, and S. Ramaswamy, "Collaborative positioning and embedded multi-sensors fusion cooperation in advanced driver assistance system," Transportation Research Part C-Emerging Technologies, vol. 29, pp. 197-213, Apr 2013.

[75] K. Bengler, K. Dietmayer, B. Farber, M. Maurer, C. Stiller, and H. Winner, "Three Decades of Driver Assistance Systems: Review and Future Perspectives," IEEE Intelligent Transportation Systems Magazine, vol. 6, no. 4, pp. 6-22, 2014.

[76] N. Trübswetter and K. Bengler, "Why should I use ADAS? Advanced driver assistance systems and the elderly: knowledge, experience and usage barriers," 2013.

[77] S. Brunner, M. Kucera, and T. Waas, "Ontologies used in robotics: A survey with an outlook for automated driving," in 2017 IEEE International Conference on Vehicular Electronics and Safety (ICVES), 2017, pp. 81-84.

\section{BIOGRAPHIES OF AUTHORS}
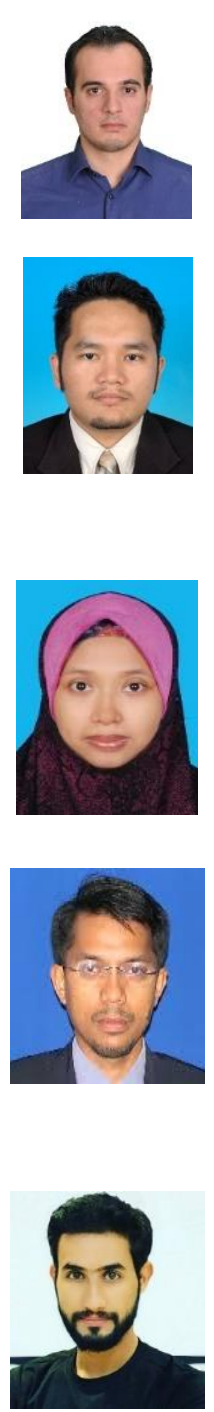

Hussein Ali Ameen received his first class B.Eng. degree in Computer Engineering in 2011 from Al-Nahrain University, Baghdad, Iraq. Then, he received his M.Sc. degree in Computer Engineering in 2015 from Al-Nahrain University, Baghdad, Iraq. Currently he is studying Ph.D in Computer Engineering at University Tun Hussein Onn Malaysia in Parit Raja, Johor, Malaysia. His research interests include RFID, computer networks, wireless communication and Vehicle to Vehicle (V2V) communication systems.

Abd Kadir Mahamad received his Bachelor of Science in Electrical Engineering (2002) and Master of Electrical Engineering (2005) from University Tun Hussein Onn Malaysia before pursuing Doctor of Philosophy (Computer Science and Electrical Engineering) at Kumamoto University, Japan (2010). He currently an Associate Professor at Faculty of Electrical and Electronic Engineering UTHM and registered as Professional Engineer. His research interests include Deep Learning, Smart City, Intelligent System applications and embedded system. He is also a senior member of IEEE, member of Institute of Engineering Malaysia (IEM) and Board of Engineering Malaysia (BEM).

Sharifah Saon is currently a Senior Lecturer in the Faculty of Electrical and Electronic Engineering, Universiti Tun Hussein Onn Malaysia, Malaysia and registered professional technologies. She received the Bachelor of Science in Electrical Engineering and Master of Electrical Engineering from Universiti Teknologi Malaysia, and Kolej Universiti Tun Hussein Onn Malaysia, Malaysia, in 2001, and 2004, respectively. Her research interest is in the area of theoretical digital signal processing, visible light communication and digital \& data communication. Including the application to Internet of Things (IoT) and bigdata analysis.

Danial Md Nor received Technical Teacher Certificate (Electrical) in 1991 from MPTKL and B.Tech degree in electrical engineering with education from the University of Technology Malaysia (UTM) Malaysia, in 1998, and the M.Sc. in Information technology from the University of Science Malaysia (USM) Penang, Malaysia, in 2001 and received his PhD in July 2016 in Electrical joint PhD programme between University of La Rochelle (ULR), France and University Tun Hussein Onn Malaysia (UTHM), Malaysia. In 2002, he joined the Department of Electrical Engineering Technology, UTHM, Malaysia, as a Lecturer, and in 2009 became a Senior Lecturer. Since December 2004, he has been with the Department of Computer Engineering, UTHM.

Kareem Ghazi currently he is computer engineering student at the University of Technology, Iraq. His research interests include Internet of Things (IoT), embedded systems, robotics and artificial intelligence. 